\title{
Women's higher likelihood of disability pension: the role of health, family and work. A 5-7 years follow-up of the Hordaland Health Study
}

\author{
Inger Haukenes ${ }^{1 *}$, Sturla Gjesdal ${ }^{1}$, Guri Rortveit ${ }^{1,2}$, Trond Riise ${ }^{1}$ and John Gunnar Mæland ${ }^{1}$
}

\begin{abstract}
Background: Women's higher risk of disability pension compared with men is found in countries with high female work participation and universal welfare schemes. The aim of the study was to examine the extent to which self-perceived health, family situation and work factors explain women's higher risk of disability pension. We also explored how these factors influenced the gender difference across educational strata.

Methods: The population-based Hordaland Health Study (HUSK) was conducted in 1997-99 and included inhabitants born in 1953-57 in Hordaland County, Norway. The current study included 5,959 men and 6,306 women in paid work with valid information on education and self-perceived health. Follow-up data on disability pension, for a period of 5-7 years, was obtained by linking the health survey to a national registry of disability pension. Cox regression analyses were employed.

Results: During the follow-up period 99 (1.7\%) men and 230 (3.6\%) women were awarded disability pension, giving a twofold risk of disability pension for women compared with men. Except for a moderate impact of self-perceived health, adjustment for family situation and work factors did not influence the gender difference in risk. Repeating the analyses in strata of education, the gender difference in risk of disability pension among the highly educated was fully explained by self-perceived health and work factors. In the lower strata of education there remained a substantial unexplained gender difference in risk.

Conclusions: In a Norwegian cohort of middle-aged men and women, self-perceived health, family situation and work factors could not explain women's higher likelihood of disability pension. However, analyses stratified by educational level indicate that mechanisms behind the gender gap in disability pension differ by educational levels. Recognizing the heterogeneity within gender may contribute to a deeper understanding of women's higher risk of disability pension.
\end{abstract}

Keywords: Disability pension, Cohort study, Educational status, Gender, Health, Occupational group, Risk factors

\section{Background}

Women's higher risk of sickness absence and disability pension is a consistent finding in countries with universal welfare schemes and high female work participation [1-3]. Different explanations have been suggested, such as women's poorer self-perceived health, higher burden of musculoskeletal pain, higher prevalence of common mental disorders, greater involvement in family and

\footnotetext{
*Correspondence: Inger.Haukenes@isf.uib.no

'Department of Public Health and Primary Health Care, University of Bergen, Kalfarveien 31, NO-5018, Bergen, Norway

Full list of author information is available at the end of the article
}

domestic work, higher preference of part-time positions, and lower status in the labour market [2,4-8].

Self- perceived health is strongly related to disability pension [6], but gender difference in this relation is scarcely examined. A Norwegian population-based study found limited impact of self-perceived health on women's excess risk of disability pension [1], while moderate impact was found among Helsinki municipal employees regarding medically confirmed sickness absence [4]. With respect to family situation, there is some evidence that financial strain, single parenthood and having a disabled spouse enhance women's risk of sickness absence [7,9]. Considering disability pension, 
neither marital status, number of children or age of children seems to explain women's excess risk $[4,10]$. However, conflicting results and a lack of studies using disability pension as outcome make it difficult to conclude.

Higher levels of education is associated step by step with increased health and lower risk of disability pension [11-13]. However, the recent gender equalization in educational achievement in Norway has not reduced the gender gap in disability pension. One reason may be that equality in educational achievement does not necessarily imply gender equality in occupational status. Women are more often employed than men in the public sector, work part time and occupy lower working-class positions with lower incomes, and are thus more exposed to work factors associated with disability pension [5,8,14]. Considering the steep educational gradient in risk of disability pension, most likely risk-factors and their impact differ across strata of education. Also, a Norwegian study found that it is far more challenging to explain disability risk among the lower educated than among the higher educated [14]. These findings point at educational levels as relevant strata for examining gender differences in disability pension. However, this perspective has not been pursued in literature.

The aim of the study was to examine the extent to which self-perceived health, family situation and work factors explain women's higher risk of disability pension. We also explored how these factors influenced the gender difference across educational strata.

\section{Methods}

\section{Study population}

The population based Hordaland Health Study (HUSK) was conducted in 1997-99 and included inhabitants born in 1953-57 in Hordaland County, Norway. HUSK was a collaboration between the National Health Screening Service, the University of Bergen and local health services. A total of 8,598 men and 9,983 women (age 40-45) participated, yielding a participation rate of $57 \%$ for men and $70 \%$ for women. Data collection was performed in two steps. Firstly, all participants underwent a physical health examination and completed a selfadministered questionnaire. In the second step the participants were randomized in four equal groups (two male and two female groups). Each of these groups was given a questionnaire with gender-specific questions and general questions about family and work and a total of 7,327 men and 8,843 women answered. The response rate in the second step was $85,4 \%$ for the men and $87,1 \%$ for the women (\% of participants). The subsample used in the current study was based on the second questionnaire and included participants who reported being in paid work (never awarded disability pension before participating in HUSK) and with valid information on educational level and self-perceived health. These criteria led to an exclusion of 1090 men and 2447 women. Further, farmers were excluded (268 men and 72 women) due to their special working conditions compared with the rest of the work force. Finally, individuals awarded disability pension the first 12 months after participating in HUSK were excluded (10 men and 18 women), in order to eliminate report bias as a result of already being in the process of applying for a disability pension [15]. The final study population consisted of 5,959 men and 6,306 women.

\section{Outcome}

Follow-up data on disability pension was obtained by linking the health survey to a national register of disability pension by means of the unique personal ID number. The outcome was award of at least $50 \%$ disability pension during follow-up, from 12 months after participating in the heath survey (HUSK) until the end of 2004 (5-7 years follow-up period). For all disability pensioners, the time interval between the date of participation in HUSK and the date of the disability pension award was calculated.

\section{Self-perceived health}

Self-perceived physical and mental health status was measured by the self-report Short Form-12 (SF-12), a validated questionnaire with well-documented psychometric properties [16]. This shorter version of the SF-36 is recommended for large population surveys such as HUSK. The questions in SF-12 mainly assess the individuals' perceived health-related limitations in daily activity, work and social relationships, thus giving a general indication of self-assessed functional ability. Weighted summary scores for perceived mental and physical health were standardized in accordance with the US norm data with a mean score of 50 (SD 10) [16]. In the analyses, the scores were divided into quartiles with the lowest quartile implying the poorest self-perceived health [17].

\section{Family situation}

Information on marital status and children in the household were used to generate three dichotomous variables: married (yes/no), ever divorced (yes/no), children $<18$ years in the household (yes/no). Another dichotomous variable signifying whether or not the spouse received social security benefits, was generated from information on the spouse's status regarding sickness/rehabilitation allowance, disability pension and unemployment benefits.

\section{Working hours per week}

The participants reported number of paid working hours per week. We recoded the information into three main categories: full-time ( $\geq 37$ hours), part-time (27-36 hours), and small part-time ( $<27$ hours). 


\section{Occupational class}

Self-reported information on branch of industry and occupation was manually converted into four-digit codes based on the International Standard Classification of Occupations, ISCO-88 (COM) [18]. Using an internationally applicable algorithm by Ganzeboom and Treiman [19], ISCO codes were recorded into the Eriksson, Goldthorpe and Portocareros occupational class scheme [20]. The following occupational classes were used: (1) Administrative and professional, (2) routine non-manual, and (3) manual. Among the first class are managers, directors, senior officials and academic professions that require at least 4 years of education. Examples of occupations in the second class are nurses, social workers, teachers in compulsory and vocational schools, clerks and home-helpers. The category of manual workers includes skilled and unskilled workers within crafts, industry, construction and service. The occupational class scheme has achieved a high degree of comparability between European countries when measuring morbidity [21]. The scheme also reflects an occupational structure of status that is associated with disability pension for both genders $[14,22]$.

\section{Education}

Information on education was acquired through responses to the following question: "What is the highest level of education you have achieved?" Options for answers were: University $\geq 4$ years, college $<4$ years, higher secondary school, vocational school, and primary + lower secondary school. We applied the following three educational levels: University/college; vocational/upper secondary and primary/lower secondary.

\section{Analyses}

We employed chi-square tests to examine the gender difference in distribution of participants by strata of independent variables. Univariate Cox regression analyses were employed to examine the association between each independent variable and disability pension, stratified by gender. To examine the gender difference in risk of disability pension, we employed a multivariate Cox regression analysis. To test whether the relationship between the covariates and risk of disability pension was different between men and women (effect modification) we included interaction terms in the Cox model when analysing the total cohort.

The independent variables were added in a predefined order, introducing self-perceived mental and physical health first: second, variables concerning family situation, followed by occupational class and, finally, working hours per week. The impact of additional health measures (self-reported medical conditions, somatic symptoms and mental health assessed by the Hospital Anxiety and Depression Scale) were also tested in the model.
The results are presented as hazard ratios (HR) with 95\% confidence intervals (CIs). The change in gender HR when introducing covariates in the model was estimated in percent by the following formula: (HR adjusted $\mathrm{HR}$ unadjusted $/ \mathrm{HR}$ unadjusted "100. A Spearman's Rank Order correlation was run to determine the relationship between educational levels and occupational class. All covariates were tested for the assumption of proportionality. No marked deviation from the proportional hazard assumption was found. The analyses were performed using SPSS (PASW) 18.0 for Windows.

\section{Ethical approval}

The study protocol was approved by the Regional Committee for Medical Research Ethics, Western Norway and by the Norwegian Data Inspectorate. Written statements of informed consent were gathered from all the participants in the current study at the time of the physical health examination.

\section{Results}

Gender difference across independent variables

The difference in the distribution of men and women across all independent variables was statistically significant, except for marriage (yes/no) and living with children (yes/no) (Table 1). There were marked differences in the distribution of men and women by occupational class and working hours per week (Table 1). A relatively higher proportion of men reported administrative and professional work, while routine non-manual work was relatively more often reported by women. Furthermore, $51 \%$ of the women had part-time work compared to $11 \%$ of the men.

\section{Gender difference in disability pension}

During the 5-7 years follow-up period, a total of 99 (1.7\%) men and 230 (3.6\%) women were awarded disability pension (Table 1 ). In both genders, lower education, manual work, part-time work and lower selfperceived physical health were associated with disability pension.

Regarding self-perceived mental health, men with the lowest scores (quartile 4) had a substantially higher risk of disability pension compared with the reference group (quartile 1). Among women the pattern was unclear, but the reference group had a significantly higher risk of disability pension compared with those in quartile 3. This difference in effect between men and women was significant (test of interaction in total cohort: $\mathrm{p}=0.001$ ). When estimating this effect of interaction, by analysing the effect of gender in strata of self-perceived mental health (data not shown), we found no gender difference in risk of disability pension among those in the lowest quartiles of self-perceived mental health. 
Table 1 Distribution of participants, cumulative incidence of disability pension (DP) and unadjusted risk of DP by covariates

\begin{tabular}{|c|c|c|c|c|c|c|c|c|c|c|c|c|c|}
\hline & \multicolumn{5}{|c|}{ Distribution } & \multicolumn{8}{|c|}{ Disability pension } \\
\hline & \multicolumn{2}{|c|}{ Men } & \multicolumn{2}{|c|}{ Women } & \multirow[b]{2}{*}{ p-value* } & \multicolumn{4}{|c|}{ Men } & \multicolumn{4}{|c|}{ Women } \\
\hline & $\mathbf{n}$ & $\%$ & $\mathbf{n}$ & $\%$ & & $\mathrm{n}$ & $\%$ & HR & $95 \% \mathrm{Cl}$ & $\mathbf{n}$ & $\%$ & HR & $95 \% \mathrm{Cl}$ \\
\hline Gender & 5959 & & 6306 & & & 99 & 1.7 & & & 230 & 3.6 & & \\
\hline Married & & & & & 0.269 & & & & & & & & \\
\hline Yes & 4481 & 75.2 & 4796 & 76.1 & & 62 & 1.4 & 1.00 & & 169 & 3.5 & 1.00 & \\
\hline No & 1478 & 24.8 & 1510 & 23.9 & & 37 & 2.5 & 1.85 & $1.23-2.78$ & 61 & 4.0 & 1.18 & $0.88-1.59$ \\
\hline Ever divorced & & & & & 0.000 & & & & & & & & \\
\hline No & 5487 & 92.1 & 5619 & 89.1 & & 83 & 1.5 & 1.00 & & 196 & 3.5 & 1.00 & \\
\hline Yes & 472 & 7.9 & 687 & 10.9 & & 16 & 3.4 & 2.31 & $1.35-3.94$ & 34 & 4.9 & 1.47 & $1.02-2.11$ \\
\hline Living with children $<18$ years & & & & & 0.206 & & & & & & & & \\
\hline Yes & 4508 & 75.7 & 4604 & 73.0 & & 66 & 1.5 & 1.00 & & 146 & 3.2 & 1.00 & \\
\hline No & 1068 & 17.9 & 1158 & 18.4 & & 22 & 2.1 & 1.43 & $0.88-2.32$ & 58 & 5.0 & 1.63 & $1.20-2.21$ \\
\hline Spouse receive social benefit & & & & & 0.000 & & & & & & & & \\
\hline No & 5412 & 90.8 & 5940 & 94.2 & & 84 & 1.6 & 1.00 & & 210 & 3.5 & 1.00 & \\
\hline Yes & 547 & 9.2 & 366 & 5.8 & & 15 & 2.7 & 1.77 & $1.02-3.06$ & 20 & 5.5 & 1.54 & $0.98-2.44$ \\
\hline Educational level & & & & & 0.000 & & & & & & & & \\
\hline University/college & 2402 & 40.3 & 2353 & 37.3 & & 26 & 1.1 & 1.00 & & 48 & 2.0 & 1.00 & \\
\hline Vocational/higher secondary & 2750 & 46.1 & 2874 & 45.6 & & 47 & 1.7 & 1.55 & $0.96-2.50$ & 106 & 3.7 & 1.80 & $1.28-2.53$ \\
\hline Primary/lower secondary & 807 & 13.5 & 1079 & 17.1 & & 26 & 3.2 & 2.94 & $1.71-5.06$ & 76 & 7.0 & 3.47 & $2.41-4.98$ \\
\hline Occupational class & & & & & 0.000 & & & & & & & & \\
\hline Administrative/professional & 2908 & 48.8 & 1481 & 23.5 & & 33 & 1.1 & 1.00 & & 27 & 1.8 & 1.00 & \\
\hline Routine non-manual & 906 & 15.2 & 3128 & 49.6 & & 10 & 1.1 & 0.97 & $0.48-1.97$ & 102 & 3.3 & 1.77 & $1.16-2.71$ \\
\hline Manual & 2010 & 33.7 & 1555 & 24.7 & & 52 & 2.6 & 2.25 & $1.46-3.49$ & 94 & 6.0 & 3.30 & $2.15-5.06$ \\
\hline Working hours per week & & & & & 0.000 & & & & & & & & \\
\hline$\geq 37$ hours & 5174 & 86.8 & 2888 & 45.8 & & 77 & 1.5 & 1.00 & & 90 & 3.1 & 1.00 & \\
\hline $27-36$ hours & 549 & 9.2 & 1769 & 28.1 & & 11 & 2.0 & 1.33 & $0.71-2.50$ & 55 & 3.1 & 0.98 & $0.70-1.37$ \\
\hline$<27$ hours & 102 & 1.7 & 1463 & 23.2 & & 5 & 4.9 & 3.38 & $1.37-8.37$ & 78 & 5.3 & 1.69 & $1.25-2.29$ \\
\hline Self-perceived mental health & & & & & 0.000 & & & & & & & & \\
\hline Quartile 1 (good) & 1626 & 27.3 & 1338 & 21.2 & & 14 & 0.9 & 1.00 & & 54 & 4.0 & 1.00 & \\
\hline Quartile 2 & 1640 & 27.5 & 1636 & 25.9 & & 14 & 0.9 & 0.99 & $0.47-2.09$ & 47 & 2.9 & 0.71 & $0.48-1.04$ \\
\hline Quartile 3 & 1351 & 22.7 & 1501 & 23.8 & & 20 & 1.5 & 1.73 & $0.87-3.42$ & 35 & 2.3 & 0.57 & $0.37-0.88$ \\
\hline Quartile 4 (poorest) & 1342 & 22.5 & 1831 & 29.0 & & 51 & 3.8 & 4.50 & $2.49-8.14$ & 94 & 5.1 & 1.28 & $0.91-1.79$ \\
\hline Self-perceived physical health & & & & & 0.000 & & & & & & & & \\
\hline Quartile 1 (good) & 1530 & 25.7 & 1641 & 26.0 & & 6 & 0.4 & 1.00 & & 18 & 1.1 & 1.00 & \\
\hline Quartile 2 & 1483 & 24.9 & 1478 & 23.4 & & 7 & 0.5 & 1.20 & $0.40-3.56$ & 21 & 1.4 & 1.28 & $0.68-2.40$ \\
\hline Quartile 3 & 1669 & 28.0 & 1410 & 22.4 & & 20 & 1.2 & 3.03 & $1.22-7.55$ & 30 & 2.1 & 1.92 & $1.07-3.44$ \\
\hline Quartile 4 (poorest) & 1277 & 21.4 & 1777 & 28.2 & & 66 & 5.2 & 13.37 & $5.80-30.84$ & 161 & 9.1 & 8.59 & $5.28-13.99$ \\
\hline
\end{tabular}

${ }^{*} \mathrm{X}^{2}$ for gender differences in distribution of participants.

Hazard ratios $(\mathrm{HR})$ and $95 \%$ confidence intervals $(95 \% \mathrm{Cl})$ from univariate Cox regression analyses.

For men, being unmarried or having a spouse on social benefits increased the risk of subsequent disability pension, while for women a higher risk was related to not having children in the household. However, none of these differences were significant (test of interaction).
In the multivariate Cox regression analysis women's higher risk of disability pension (crude $\mathrm{HR}=2.21,95 \% \mathrm{CI}=$ $1.75-2.80$ ) was attenuated with a $15 \%$ reduction in the hazard ratio, when adjusting for self-perceived mental and physical health (Table 2). Additional adjustments for variables 
pertaining to family situation, occupational class and working hours per week did not further reduce women's excess risk, leaving a substantial unexplained gender difference in the final model $(\mathrm{HR}=1.95,95 \% \mathrm{CI}=1.43-2.65)$. Adjustment for additional health measures did not contribute to further explaining the gender difference, and were not incuded.

Repeating the analyses in strata defined by educational level, self-perceived health, occupational class and working hours per week were clearly associated with a risk of disability pension among highly educated women, while only self-perceived health was associated with lower educated women (Table 3). The disability risk among women with high education (crude $\mathrm{HR}=1.88,95 \% \mathrm{CI}=1.17-3.03$ ) was fully explained in the final model ( $\mathrm{HR}=1.10,95 \%$ $\mathrm{CI}=0.58-2.08)$, whereas this was not the case for women with lower education. The correlation $\left(\mathrm{r}_{\mathrm{s}}\right)$ between educational level and occupational class was $0.507, p<0.001$.

\section{Discussion}

\section{Main results}

In a Norwegian cohort of middle-aged men and women, we found no adequate explanation for women's higher likelihood of disability pension, except for a moderate impact of self-perceived health. Further adjustment for family situation, occupational class and working hours per week did not influence women's higher disability risk in the total cohort. However, in analyses stratified by educational level, these factors fully explained women's excess risk of disability pension among the highly educated, but not among the less educated.

Table 2 Risk of disability pension among women compared to men, in a cumulative Cox regression model

\begin{tabular}{|c|c|c|c|c|c|c|c|c|c|c|}
\hline & \multicolumn{2}{|c|}{ Model 1} & \multicolumn{2}{|c|}{ Model 2} & \multicolumn{2}{|c|}{ Model 3} & \multicolumn{2}{|c|}{ Model 4} & \multicolumn{2}{|c|}{ Model 5} \\
\hline & HR & $95 \% \mathrm{Cl}$ & HR & $95 \% \mathrm{Cl}$ & HR & $95 \% \mathrm{Cl}$ & HR & $95 \% \mathrm{Cl}$ & HR & $95 \% \mathrm{Cl}$ \\
\hline Men & 1 & & 1 & & 1 & & 1 & & 1 & \\
\hline Women & 2.21 & $1.75-2.80$ & 1.87 & $1.48-2.37$ & 1.91 & $1.48-2.46$ & 2.04 & $1.56-2.68$ & 1.95 & $1.43-2.65$ \\
\hline Mental health (ref = Quartile 1) & & & 1 & & 1 & & 1 & & 1 & \\
\hline Quartile 2 & & & 1.17 & $0.82-1.65$ & 1.20 & $0.83-1.75$ & 1.23 & $0.84-1.78$ & 1.24 & $0.85-1.83$ \\
\hline Quartile 3 & & & 1.02 & $0.71-1.46$ & 1.10 & $0.75-1.59$ & 1.10 & $0.75-1.62$ & 1.12 & $0.76-1.65$ \\
\hline Quartile 4 & & & 2.04 & $1.53-2.72$ & 1.98 & $1.45-2.71$ & 1.96 & $1.43-2.70$ & 1.96 & $1.42-2.72$ \\
\hline Physical health (Quartile 1) & & & 1 & & 1 & & 1 & & 1 & \\
\hline Quartile 2 & & & 1.49 & $0.86-2.59$ & 1.69 & $0.94-3.03$ & 1.63 & $0.91-2.93$ & 1.63 & $0.91-2.92$ \\
\hline Quartile 3 & & & 2.50 & $1.53-4.08$ & 2.70 & $1.60-4.58$ & 2.49 & $1.47-4.24$ & 2.34 & $1.37-4.00$ \\
\hline Quartile 4 & & & 10.32 & $6.76-15.75$ & 10.59 & $6.67-16.81$ & 9.19 & $5.77-14.63$ & 8.64 & $5.42-13.77$ \\
\hline Married (ref = yes) & & & & & 1 & & 1 & & 1 & \\
\hline No & & & & & 0.78 & $0.53-1.14$ & 0.76 & $0.51-1.13$ & 0.76 & $0.50-1.14$ \\
\hline Ever divorced (ref = no) & & & & & 1 & & 1 & & 1 & \\
\hline Yes & & & & & 1.83 & $1.17-2.86$ & 1.75 & $1.11-2.77$ & 1.86 & $1.16-2.97$ \\
\hline Children < 18 y at home (ref = yes) & & & & & 1 & & 1 & & 1 & \\
\hline No & & & & & 1.51 & $1.14-1.99$ & 1.47 & $1.11-1.95$ & 1.56 & $1.17-2.07$ \\
\hline Spouse social benefit (ref = no) & & & & & 1 & & 1 & & 1 & \\
\hline Yes & & & & & 1.49 & $1.03-2.17$ & 1.44 & $0.99-2.09$ & 1.52 & $1.05-2.21$ \\
\hline Administrative/professional class & & & & & & & 1 & & 1 & \\
\hline Routine non-manual class & & & & & & & 1.22 & $0.87-1.73$ & 1.23 & $0.86-1.74$ \\
\hline Manual class & & & & & & & 2.09 & $1.52-2.87$ & 2.12 & $1.51-2.94$ \\
\hline$>37$ working hours per week & & & & & & & & & 1 & \\
\hline $27-36$ & & & & & & & & & 0.88 & $0.63-1.23$ \\
\hline$<27$ & & & & & & & & & 1.46 & $1.05-2.02$ \\
\hline
\end{tabular}

Hazard ratios (HR) and 95\% confidence intervals $(95 \% \mathrm{Cl})$ from multivariate Cox regression models.

Model 1: Gender only.

Model 2: Model $1+$ self-perceived health (mental and physical).

Model 3: Model $2+$ family situation (married/divorced, living with children $<18$ years, spouse receives social benefit).

Model 4: Model 3 + occupational class.

Model 5: Model $4+$ working hours per week. 
Table 3 Risk of disability pension among women compared to men in three educational groups

\begin{tabular}{|c|c|c|c|c|c|c|c|c|c|c|}
\hline \multirow[t]{2}{*}{ Educational level } & \multicolumn{2}{|c|}{ Model 1} & \multicolumn{2}{|c|}{ Model 2} & \multicolumn{2}{|c|}{ Model 3} & \multicolumn{2}{|c|}{ Model 4} & \multicolumn{2}{|c|}{ Model 5} \\
\hline & HR & $95 \% \mathrm{Cl}$ & HR & $95 \% \mathrm{Cl}$ & HR & $95 \% \mathrm{Cl}$ & HR & $95 \% \mathrm{Cl}$ & HR & $95 \% \mathrm{Cl}$ \\
\hline \multicolumn{11}{|l|}{ University / college } \\
\hline Women $($ men $=$ ref) & 1.88 & $1.17-3.03$ & 1.48 & $0.91-2.39$ & 1.69 & $1.00-2.86$ & 1.45 & $0.82-2.57$ & 1.10 & $0.58-2.08$ \\
\hline \multicolumn{11}{|c|}{ Vocational/high secondary } \\
\hline Women (men = ref) & 2.19 & $1.55-3.08$ & 1.98 & $1.40-2.80$ & 1.96 & $1.36-2.81$ & 2.40 & $1.63-3.54$ & 2.14 & $1.37-3.37$ \\
\hline \multicolumn{11}{|l|}{ Primary/secondary } \\
\hline Women $($ men $=$ ref) & 2.22 & $1.42-3.47$ & 1.86 & $1.19-2.91$ & 1.88 & $1.15-3.05$ & 1.99 & $1.18-3.35$ & 2.67 & $1.50-4.77$ \\
\hline
\end{tabular}

Hazard ratios (HR) and 95\% confidence intervals $(95 \% \mathrm{Cl})$ from multivariate Cox regression models.

Model 1: Gender only.

Model 2: Model $1+$ self-perceived health (mental and physical).

Model 3: Model $2+$ family situation (married/divorced, living with children $<18$ years, spouse receives social benefit).

Model 4: Model 3 + occupational class.

Model 5: Model $4+$ working hours per week.

\section{Self-perceived health}

Some have argued that health plays only a minor role in exit from working life in modern societies [23]. However, several studies have shown that self-perceived health is a strong predictor of subsequent sickness absence and disability pension across gender and social class $[6,17,24-26]$. In the current study self-perceived physical health was strongly associated with disability pension in both genders, while self-perceived mental health was associated only among men. However, in the multivariate analyses both dimensions of self-perceived health contributed to explain women's excess disability risk. This impact was found in the total cohort and in strata of educational level. A Norwegian study found that among individuals on sick leave for more than eight weeks due to musculoskeletal disorders, women less than 50 years of age had a higher risk of disability pension compared with men in the same age group [5]. Self-perceived physical health may reflect musculoskeletal disorders in both genders, but the higher impact on women's disability risk may be due to an earlier chronicity among women. Further, Laaksonen et al. found that self-perceived health and self-reported diagnoses explained the gender difference in long-term sickness absence among middle-aged [4]. In a Norwegian study, selfperceived global health had little impact on women's excess risk, while adding mental distress significantly reduced the gender difference [1]. However, the addition of several self-reported health measures in the current study provided no further explanation of women's excess risk of disability pension.

The relation between self-perceived mental health and risk of disability pension did not display a linear trend, a finding that may be related to the construction of the physical and mental summary SF-12 scales providing uncorrelated (orthogonal) factors, a construct that is theoretically unlikely [27]. Using the multidimensional SF-36 questionnaire, Laaksonen et al. found a strong association between self-perceived physical health and sickness absence while mental health was only weakly associated [26]. Studies using the Hospital Anxiety and Depression Scale (HADS), on the other hand, have found linear associations between higher scores on selfreported anxiety/depression and subsequent disability pension $[28,29]$.

\section{Family situation}

In line with our findings, a Norwegian study found that living with children younger than 7 years of age diminished the likelihood of disability pension among women [13]. However, the current study supports the general impression that marital status, children in the household or a retired spouse all have little impact on the gender difference in disability pension $[4,5,8]$. Women's increased participation in working life has brought about some changes in traditional family roles and expanded the use of part-time jobs. With respect to the interface between work and family, findings indicate that both genders are at risk of sickness absence when experiencing negative interference from work on the family situation $[30,31]$.

\section{Occupational social class}

As confirmed in the literature, the risk of disability pension increases substantially with lower occupational social class $[14,22]$. Some studies have suggested that women's excess risk of sickness absence and disability pension is more likely explained by vertical gender segregation than by horizontal segregation [2,32]. Vertical segregation refers to the unequal gender distribution in occupational social class, while horizontal segregation denotes the tendency of men and women to work in different occupations [33]. In the current study, controlling for occupational class (vertical segregation) in the total cohort, did not contribute towards explaining women's excess risk of disability pension, thus confirming the findings from a previous Norwegian study [1]. 
Nevertheless, in the analyses stratified by educational level we found that the risk of disability pension among highly educated women was considerably influenced by occupational class. One explanation is that higher education among women, more frequently than among men, is translated into occupational classes with less power, less autonomy and less status and thereby implies an excess risk of disability pension [34]. In the current study, the different distribution of men and women by occupational class supports this interpretation. Among the lower educated, occupational class did not explain women's higher disability risk, thus supporting studies that find male workplaces within the manual occupations particularly hazardous to health $[32,35]$.

\section{Part-time work}

In the current study, part-time work less than 27 hours per week was associated with increased risk of disability pension in both genders, but did not contribute to explain women's higher risk of disability pension in the total cohort $[5,13]$. One might question whether the risks associated with part-time work are linked with the reduced number of hours at the work place, and conversely the higher number of hours outside the work place, or are merely a reflection of poor health and reduced work ability among part-time workers. Considering the unequal distribution of men and women in part-time positions, reasons for part-time work most likely differ by gender. In the current study, the relatively high risk of disability pension among men working parttime indicates reduced work ability. Among women, however, part-time work is often preferred to ease the double burden of work and family obligations $[7,36]$. When working hours per week did not influence the gender difference in disability pension in the total cohort, this may be related to the unequal gender distribution among part-time workers and the selection of men with reduced work ability into part-time positions.

However, in the analyses stratified by education, working hours per week contributed to explain women's excess risk of disability pension among the highest and second highest educated, but not among the lowest educated. Again, the impact of gendered distribution, selection effects and adjustment for health make it difficult to interpret the findings. In conclusion, working hours per week is an ambiguous variable that needs to be combined with additional information when interpreting impact on gender difference in disability pension.

\section{The unexplained risk}

Population-based studies of risk factors for disability pension give valuable information about risks that are common for both genders and for men and women separately $[11,12,14]$. However, there is a need for studies that aim at examining the gender difference as such [1]. In the current study, the substantial unexplained disability risk among women versus men, after adjusting for health, family and work factors, mirrors a complexity that may need a gender difference approach in order to be understood.

Firstly, occupational health research has accumulated far more knowledge of health hazards related to male working life than female [37]. Secondly, widely used tools to assess the psychosocial working environment were developed within a male working force paradigm, and may lack essential perspectives related to women's multiple roles in society [38,39]. Emotional demands, rewards at work, management quality and role conflicts may be especially important for explaining the gender gap in longterm sickness absence and disability pension [34]. Thirdly, education in modern society is not a onetime occurrence, but rather a continuous process throughout the working career. The ability to cope with changing work tasks, technology and decision processes is probably vital for conceiving work as a meaningful and significant part of one's life. Lower education combined with part-time work gives women fewer options regarding jobs, less opportunity to attend training, less coping experience and a higher risk of exclusion as a result of reorganization and downsizing. These factors need to be addressed in further studies of gender difference.

\section{Limitations}

Firstly, the response rate was higher for women than for men, $70 \%$ versus $57 \%$ respectively, which opens for possible selection bias related to genders. A study of nonparticipants in HUSK found that $5.5 \%$ of the male nonparticipants and $8.8 \%$ of the females were awarded disability pension after the HUSK survey was performed. Among participants the percentages were $2.7 \%$ for men and $5.2 \%$ for women. However, the study found no significant gender differences in the association between nonparticipation and awards of disability pension [40]. This finding indicates that the gender distribution in $\mathrm{cu}-$ mulative incidence of disability recipients in the current study was probably not biased by the gender difference in nonparticipation.

Secondly, typical for non-participants in populationbased studies are lower educational level and lower income [41]. Since this under-representation related to level of education and income, is most likely similar for men and women, we do not think that our risk estimates are flawed by selective participation. Further, the relatively low incidence of male disability pensioners may impose some restrictions on the interpretation of the analyses. Finally, the information collected at baseline was cross-sectional, thus preventing identification of causal paths between independent variables. 


\section{Strengths}

Our study is based on a linkage between HUSK and the National Insurance Administration's records of disability pensions awarded to Norwegian inhabitants from 1992 onwards. This register is complete, accurate and independent of exposure data obtained in the Hordaland Health survey. The study thus avoids the problem of attrition. The self-reported information at baseline was collected without participants or administrators being aware of future research hypotheses.

Further, the follow-up period from 1997 till 2004 was a period without major changes in Norwegian disability policy with the potential to alter the cumulative incidence by gender. Only minor fluctuations in incidence of disability pension awards were present during this period. The study design excluded individuals awarded disability pension up to 12 months after baseline, thus decreasing the risk of biased information from participants in the process of being awarded disability pension [42]. Also, the current birth cohorts represent an age group with few incidences of pregnancies and maternity leaves that may influence baseline reporting of health and working hours per week.

\section{Conclusion}

Except for a moderate impact of self-perceived health, family situation and work factors did not explain women's higher risk of disability pension in a middleaged cohort. However, in analyses stratified by educational level, these factors explained women's excess risk of disability pension among the highly educated, but not among the lower educated.

Our results indicate that mechanisms behind the gender gap in disability pension differ by educational levels. Recognizing the heterogeneity within gender may contribute to a deeper understanding of women's higher risk of disability pension.

\section{Competing interests}

The authors declare that they have no competing interests.

\section{Authors' contributions}

IH conceived the study, performed the data analysis, coordinated the study and drafted the manuscript. SG participated in the interpretation of the results and revised the manuscript for important content. GR participated in interpretation of the results and revised the manuscript for important content. TR advised the statistical analyses and revised the manuscript for important content. JMG participated in conceiving the study, advised the statistical analyses, interpretation of the results and drafting the manuscript. All authors have read and approved the final manuscript.

\section{Acknowledgement}

The data collection was conducted as part of HUSK (the Hordaland Health Study 1997-99) in collaboration with the Norwegian National Health Screening Service. Inger Haukenes received a grant from the University of Bergen, Norway, during this work.
Funding

Inger Haukenes received a grant from the University of Bergen, Norway, during this work.

\section{Author details}

${ }^{1}$ Department of Public Health and Primary Health Care, University of Bergen, Kalfarveien 31, NO-5018, Bergen, Norway. ${ }^{2}$ Research Unit for General Practice, Uni Health, Bergen, Kalfarveien 31 NO-5018, Bergen, Norway.

Received: 22 February 2012 Accepted: 28 August 2012

Published: 31 August 2012

\section{References}

1. Claussen B, Dalgard OS: Disability pensioning: the gender divide can be explained by occupation, income, mental distress and health. Scand J Public Health 2009, 0:1-8.

2. Laaksonen M, Mastekaasa A, Martikainen P, Rahkonen O, Piha K, Lahelma E: Gender differences in sickness absence - the contribution of occupation and workplace. Scand J Work Environ Health 2010, 36:394-403.

3. Smeby L, Bruusgaard D, Claussen B: Sickness absence: could gender divide be explained by occupation, income, mental distress and health? Scand J Public Health 2009, 37:674-681.

4. Laaksonen M, Martikainen P, Rahkonen O, Lahelma E: Explanations for gender differences in sickness absence: evidence from middle-aged municipal employees from Finland. Occup Environ Med 2008, 65:325-330.

5. Gjesdal S, Bratberg E, Maeland JG: Gender differences in disability after sickness absence with musculoskeletal disorders: five-year prospective study of 37,942 women and 26,307 men. BMC Musculoskelet Disord 2011, $12: 37$.

6. Pietilainen O, Laaksonen M, Rahkonen O, Lahelma E: Self-rated health as a predictor of disability retirement - the contribution of III-Health and working conditions. PLOS One 2011, 6:e25004.

7. Bratberg E, Dahl SA, Risa AE: 'The Double Burden' Do combinations of career and family obligations increase sickness absence among Women. Eur Sociol Rev 2002, 18:233-249.

8. Albertsen K, Lund T, Christensen KB, Kristensen TS, Villadsen E: Predictors of disability pension over a 10-year period for men and women. Scand J Public Health 2007, 35:78-85.

9. Voss M, Josephson M, Stark S, Vaez M, Alexanderson K, Alfredsson L, Vingård $E$ : The influence of household work and of having children on sickness absence among publicly employed women in Sweden. Scand J Public Health 2008, 36:564-572.

10. Karlsson NE, Carstensen JM, Gjesdal S, Alexanderson KA: Risk factors for disability pension in a population-based cohort of men and women on long-term sick leave in Sweden. Eur J Public Health 2008, 18:224-231.

11. Bruusgaard D, Smeby L, Claussen B: Education and disability pension: a stronger association than previously found. Scand J Public Health 2010, $0: 1-5$

12. Krokstad S, Westin S: Disability in society-medical and non-medical determinants for disability pension in a Norwegian total county population study. Soc Sci Med 2004, 58:1837-1848.

13. Gjesdal S, Bratberg E: The role of gender in long-term sickness absence and transition to permanent disability benefits. Results from a multiregister based, prospective study in Norway 1990-1995. Eur J Public Health 2002, 12:180-186.

14. Krokstad S, Johnsen $\mathrm{R}$, Westin S: Social determinants of disability pension: a 10-year follow-up of 62000 people in a Norwegian county population. Int J Epidemiol 2002, 31:1183-1191.

15. Overland S, Glozier N, Henderson M, Maeland JG, Hotopf M, Mykletun A: Health status before, during and after disability pension award: the Hordaland Health Study (HUSK). Occup Environ Med 2008, 65:769-773.

16. Ware J Jr, Kosinski M, Keller SD: A 12-Item Short-Form Health Survey: construction of scales and preliminary tests of reliability and validity. Med Care 1996, 34:220-233.

17. Harkonmaki K, Rahkonen O, Martikainen P, Silventoinen K, Lahelma E: Associations of SF-36 mental health functioning and work and family related factors with intentions to retire early among employees. Occup Environ Med 2006, 63:558-563.

18. Statistics Norway: Standard Classification of Occupation. Oslo: Kongsvinger; 1999. 
19. Ganzeboom HBG, Treiman DJ: Internationally comparable measures of occupational status for the 1988 International Standard Classification of Occupations. Soc Sci Res 1996, 25:201-239.

20. Erikson R, Goldthorpe JH: Concepts, data, and strategies of enquiry. In The Constant Flux: A Study of Class Mobility in Industrial Societies. Edited by Erikson R, Goldthorpe JH. Oxford: Clarendon Press; 1992:28-64.

21. Cavelaars $A E$, Kunst $A E$, Geurts JJ, Helmert U, Lundberg $O$, Mielck A, Matheson J, Mizrahi A, Mizrahi A, Rasmussen N, Spuhler T, Mackenbach JP: Morbidity differences by occupational class among men in seven European countries: an application of the Erikson-Goldthorpe social class scheme. Int J Epidemio/ 1998, 27:222-230.

22. Haukenes I, Mykletun A, Knudsen AK, Hansen HT, Maeland JG: Disability pension by occupational class - the impact of work-related factors: The Hordaland Health Study Cohort. BMC Publ Health 2011, 11:406.

23. Ostby KA, Orstavik RE, Knudsen AK, Reichborn-Kjennerud T, Mykletun A: Health problems account for a small part of the association between socioeconomic status and disability pension award. Results from the Hordaland Health Study. BMC Publ Health 2011, 11:12.

24. Hanebuth D, Meinel M, Fischer JE: Health-related quality of life, psychosocial work conditions, and absenteeism in an industrial sample of Blue- and White-Collar employees: a comparison of potential Predictors. J Occup Environ Med 2006, 48:28-37.

25. Taimela S, Laara E, Malmivaara A, Tiekso J, Sintonen H, Justen S, Aro T: Selfreported health problems and sickness absence in different age groups predominantly engaged in physical work. Occup Environ Med 2007, 64:739-746.

26. Laaksonen M, Kaaria SM, Leino-Arjas P, Lahelma E: Different domains of health functioning as predictors of sickness absence-a prospective cohort study. Scand J Work Environ Health 2011, 37:213-218.

27. Nortvedt MW, Riise T, Myhr KM, Nyland HI: Performance of the SF-36, SF12 , and RAND-36 summary scales in a multiple sclerosis population. Med Care 2000, 38:1022-1028.

28. Mykletun A, Overland S, Dahl AA, Krokstad S, Bjerkeset O, Glozier N, Aaro LE, Prince M: A population-based cohort study of the effect of common mental disorders on disability pension awards. Am J Psychiatry 2006, 163:1412-1418.

29. Knudsen AK, Overland S, Aakvaag HF, Harvey SB, Hotopf M, Mykletun A: Common mental disorders and disability pension award: seven year follow-up of the HUSK study. J Psychosom Res 2010, 69:59-67.

30. Byron K: A Meta-analytic review of work-family conflict and its antecedents. J Vocat Behav 2005, 67:169-198.

31. Vaananen A, Kumpulainen R, Kevin MV, Ala-Mursula L, Kouvonen A, Kivimaki $M$, et al: Work-family characteristics as determinants of sickness absence: a large-scale cohort study of three occupational grades. $J$ Occup Health Psychol 2008, 13:181-196.

32. Mastekaasa A, Dale-Olsen H: Do women or men have the less healthy jobs? An analysis of gender differences in sickness absence. Eur Sociol Rev 2000, 16:267-286.

33. Blackburn RM, Browne J, Brooks B, Jarman J: Explaining gender segregation. Br J Sociol 2002, 53:513-536.

34. Labriola M, Holte KA, Christensen KB, Feveile $H$, Alexanderson $K$, Lund $T$ : The attribution of work environment in explaining gender differences in long-term sickness absence: results from the prospective DREAM study. Occup Environ Med 2011, 9:703-705.

35. Stattin M, Jarvholm B: Occupation, work environment, and disability pension: a prospective study of construction workers. Scand J Public Health 2005, 33:84-90.

36. Lidwall U, Marklund S, Voss M: Work-family interference and long-term sickness absence: a longitudinal cohort study. Eur J Public Health 2010, 20:676-681.

37. Annandale E, Hunt K: Gender inequalities in health: research at the crossroads. In Gender inequalities in health. 1st edition. Edited by Annandale E, Hunt K. Buckingham: Open University Press; 2000:1-35.

38. Karasek R: Job demands, job decision latitude, and mental strain: implications for job redesign. Adm Sci Q 1979, 24:285-308.

39. Ostlund G, Cedersund E, Hensing G, Alexanderson K: Domestic strain: a hindrance in rehabilitation? Scand J Caring Sci 2004, 18:49-56.
40. Knudsen AK, Hotopf M, Skogen JC, Overland S, Mykletun A: The health status of nonparticipants in a population-based health study: The Hordaland Health Study. Am J Epidemiol 2010, 11:1306-1314

41. Korkeila K, Suominen S, Ahvenainen J, Ojanlatva A, Rautava P, Helenius H, Koskenvuo M: Non-response and related factors in a Nation-Wide health survey. Eur J Epidemiol 2001, 17:991-999.

42. Overland S, Glozier N, Maeland JG, Aaro LE, Mykletun A: Employment status and perceived health in the Hordaland Health Study (HUSK). BMC Publ Health 2006, 6:219.

doi:10.1186/1471-2458-12-720

Cite this article as: Haukenes et al: Women's higher likelihood of disability pension: the role of health, family and work. A 5-7 years follow-up of the Hordaland Health Study. BMC Public Health 2012 12:720.

\section{Submit your next manuscript to BioMed Central and take full advantage of:}

- Convenient online submission

- Thorough peer review

- No space constraints or color figure charges

- Immediate publication on acceptance

- Inclusion in PubMed, CAS, Scopus and Google Scholar

- Research which is freely available for redistribution

Submit your manuscript at www.biomedcentral.com/submit
C) BioMed Central 